\title{
Sistema de Vigilância Alimentar e Nutricional. Frustrações, Desafios e Perspectivas
}

\section{Food and Nutritional Surveillance System. Frustrations, Challenges and Perspectives}

\section{Bertoldo K. G. de Arruda'}

\begin{abstract}
ARRUDA, B. K. G. de. Food and Nutritional Surveillance System. Frustrations, Challenges and Perspectives. Cad. Saúde Públ., Rio de Janeiro, 8 (1): 96-101, jan/mar, 1992.

The author reports the importance of food and nutritional surveillance, the frustations experienced during its implementation, and challenges faced in the development of Sisvan, analysing their varions dimensions - political, technical, organizational, operational and social - as well as recent perspectives generated by the recognition of nutritional aspects as a mandatory reference for social and economic policies. Emphasis is given to surveillance as a basically local activity in nature, supported by decentralization proposals which are materialized in the municipalization of health services.
\end{abstract}

Keywords: Nutritional Surveillance; Food Surveillance

\section{INTRODUÇÃO}

Nas últimas décadas, a sociedade brasileira sofreu a influência de diferentes estilos de desenvolvimento, os quais não alcançaram plenamente os objetivos almejados, em termos de resgate da dívida social.

A convocação mais recente dos vários segmentos da sociedade é para participar de um projeto de reconstrução nacional, cuja tônica é a modernidade, atingível mediante propostas de transformações profundas nos setores sociais, econômicos e culturais. $O$ objetivo maior é possibilitar o crescimento e a justiça social, consubstanciados na melhoria da qualidade de vida da população, que se reflete, sem dúvida, de maneira sensível e objetiva, nos perfis de saúde e nutrição.

Se aqueles estilos de desenvolvimento foram demarcados pelo excessivo normativismo estatal, agora o propósito é orientar-se pela ampliação e fortalecimento do liberalismo, com vistas à modernização das estruturas produtivas e a inserir o Brasil entre os países do Primeiro Mundo.

\footnotetext{
1 Instituto Materno Infantil de Pernambuco. Rua dos Coelhos 300, Recife, PE, 50070, Brasil.
}

Porém, é inegável que modernização não significa apenas progresso, liberdade política, eliminação das desigualdades, em especial no distributivismo da renda, avanços no campo científico e tecnológico, na formação de competências e na difusão e aplicação do conhecimento. Significa também - e principalmente - a conquista da cidadania e de novas formas de convivência social.

Por isso, é bom lembrar, as sociedades que melhor responderam aos desafios do desenvolvimento caracterizaram-se por serem essencialmente informacionais, participativas, demonstrando a importância e a efetividade da informação para atingir a modernidade, em clima democrático.

Estas considerações são oportunas no momento em que países do Terceiro Mundo buscam atingir padrões ocidentais, uma vez que, admitem os analistas (Cadermartori, 1990), dentre os fatores decisivos na disputa das capacidades produtivas das naçōes, determinantes para o desenvolvimento econômico e social, a informação inscreve-se prioritariamente. Todavia, o relevo que lhe é concedido não expressa o culto da informação, facilitado pelo avanço na tecnologia computacional, que pode transformá-la em um fim em si mesma. 
Felizmente, na área da saúde, já é reconhecido o seu valor como recurso organizacional e gerencial, capaz de. instrumentar, de forma fidedigna e oportuna, não só os niveis decisórios institucionais, por exemplo, na identificação, utilização, acompanhamento e avaliação de modelos de intervenção, mas, o que é igualmente significativo, apoiar a atuação dos profissionais no contato diário com os usuários dos serviços, a nível local, bem como a mobilização da comunidade.

Em saúde, o emprego mais difundido, lógico, articulado e dinâmico da informação ocorre na Vigilância Epidemiológica. No campo da nutrição, ao evidenciarem os especialistas a necessidade também do enfoque multicausal e multissetorial dos problemas, começaram, nos idos de 1960, a se preocupar com ações de vigilância alimentar e nutricional. Os trabalhos nesse sentido despertaram o interesse dos níveis políticos, culminando, em 1974, com a realização da Conferência Mundial de Alimentos, em Roma, constando de uma de suas Resoluções a recomendação de serem estabelecidos Sistemas de Vigilância Alimentar e Nutricional.

\section{FRUSTRAÇÕES}

Com o advento da Conferência Mundial de Alimentos, aumentou expressivamente o número de países que dispensaram grandes esforços para melhoria da situação nutricional de suas populaçōes. Apesar da euforia despertada por essa Conferência e numerosas reuniōes posteriores, ocorreram frustrações dos técnicos e cientistas, pois nem sempre eram aplicadas as medidas mais indicadas onde se manifestavam as maiores necessidades. A partir daí, a vigilância alimentar e nutricional foi convertida em tema obrigatório da programação desenvolvida pela maioria dos paises, verificando-se $\mathrm{cm}$ muitos deles, após o entusiasmo inicial dos responsáveis, o surgimento de desencantos, mesmo naquelas situações em que havia ajuda significativa de organismos internacionais.

São poucos os países que revelam resultados animadores na implementação da vigilância alimentar e nutricional, identificáveis mais em relação a atividades intra-setoriais, particularmente do setor saúde, rotulando-as, a meu ver, sob a denominação mais adequada de vigilância nutricional.

Múltiplas razões concorreram para tais frustrações, sendo destacadas pelos peritos as seguintes:

- embora as políticas governamentais enfatizem a adoção de medidas na área nutricional, na prática se observa um descompromisso, com o distanciamento entre o discurso e a aplicação, dificultando a implementação do Sisvan;

- em muitas situações, os sistemas formulados, embora teoricamente corretos, são demasiado complexos, tornando o Sisvan inoperável frente às condições e disponibilidades institucionais; - o empenho em conseguir a participação multissetorial, conceitualmente indispensável, pode ser entrave para o Sisvan. Às vezes, por conflitos de interesses, alguns setores envolvidos se sentem desmotivados a participar, somando-se o fato de inexistirem modelos realistas de coordenação;

- uma freqüente preocupação é criar estruturas técnico-administrativas exclusivas para o Sisvan, paralelamente a outras estruturas da organização onde se inserem, de tal modo que passa a ser considerado como um núcleo isolado, o que cria obstáculo à colaboração desejada;

- a vinculação excessiva a apoios externos, sem consolidar recursos próprios, é outra limitante do Sisvan quando ocorre a retirada daquelas contribuições, em especial de organismos internacionais, que não podem se responsabilizar pela sua manutenção;

- uma falha injustificável é o Sisvan não se interligar efetivamente ao subsistema de vigilância epidemiológica, integrante do sistema de informação em saúde, pois a maneira como o Sisvan é implantado constitui fator determinante de sua sobrevivência.

\section{DESAFIOS}

É fato inconteste que a tecnologia da informação está provocando maiores mudanças em nossas vidas - e nas instituições - do que é 
geralmente percebido. Enquanto as mudanças institucionais são lentas, a tecnologia avança rapidamente e, no caso do Sisvan, a velocidade, oportunidade, continuidade e qualidade da informação representam fatores que, ao se degradarem, levam à perda da eficiência e credibilidade do sistema como um todo.

Outrossim, a eficácia da informação aumenta à medida que a organização aprende a administrá-la corretamente. Daí ser necessário o conhecimento da realidade organizacional, a fim de selecionar o que é relevante e pertinente para as decisões, visando evitar a superestimação do Sisvan como instrumento de importância crítica na organização.

São inúmeros os desafios que se apresentam ao desenvolvimento do Sisvan, cuja identificação e enfrentamento é imprescindível. Esses desafios podem ser grupados nas seguintes dimensōes:

\section{Dimensão Política}

É habitual, e até consensual, a afirmação de que, no campo da saúde e da alimentação e nutrição, tudo depende da vontade política, da decisão política. É uma assertiva correta, mas deve-se levar em conta o fato de que a vontade e decisão políticas não se exercem no vazio, pois alguns pressupostos são necessários para respaldá-las. Dentre esses pressupostos, avulta a necessidade da informação, revestida de elevado teor de confiabilidade e representatividade.

Destarte, o Sisvan terá pouco valor se não fornecer dados que sejam úteis para a tomada de decisões, que é a manifestação concreta da vontade política. Além de ser valorizado pela decisão produzida, só terá sentido caso se caracterize pela oportunidade, para que $o$ processo decisório não se exerça em descompasso com a realidade.

É preciso insistir na estreita articulação planejamento/Sisvan. Há enriquecimento mútuo: do Sisvan, porque proporciona os dados de que necessita o planejamento, e do planejamento, porque, ao utilizar a informação que procede do Sisvan, será mais eficaz, pois se baseia em dados que se originam da dinâmica das mudanças que se produzem em situações que não podem ser observadas em cortes transversais, isto é, em dados que são coletados apenas uma vez.

\section{Dimensão Técnica}

Preliminarmente, convém referir que o valor da informação é função da qualidade dos dados iniciais, do seu grau de precisão e forma de tratamento, do modo de desagregação a que sejam submetidos, da maneira como são divulgados, e também devem ser medidos pelo seu custo.

Daí o cuidado em termos da sofisticação de indicadores, a fim de que não constituam uma limitante para que o Sisvan adquira significação epidemiológica. Esses indicadores devem apresentar, além de níveis aceitáveis de especificidade, sensibilidade, confiabilidade e representatividade, margens razoáveis de simplicidade para facilidades de obtenção do elenco minimo definido. Com isso, evitam-se solicitações freqüentes de mais informações do que aquelas efetivamente necessárias para que o Sisvan cumpra a sua maior finalidade: informação/ação.

Importa levar em conta o fluxo da informação, desde a coleta, processamento, análise, interpretação até a transferência aos niveis decisórios, dando particular atenção à retroalimentação, porque estimula e reforça os niveis geradores a prestarem melhor atendimento e a manterem a boa qualidade dos dados. Indiretamente, o Sisvan deve buscar mecanismos para avaliar e melhorar técnicas e procedimentos destinados a gerar os dados, merecendo destaque os seguintes aspectos:

- disponibilidade, cobertura, credibilidade e qualidade das fontes de coleta;

- habilitação, compromisso e interesse do pessoal encarregado dos registros;

- simplicidade e adequabilidade dos formulários;

- legibilidade e exatidão dos registros.

A regularidade dessa análise crítica contribui para a correção de possiveis ertos ou omissões e estimula a considerar a validade da informação. 


\section{Dimensão Organizacional}

A estrutura organizativa do Sisvan deve situar-se em nivel hierárquico que permita sua influência no planejamento e na implementação de programas e projetos, contando com uma equipe técnico-administrativa a tempo integral. Outrossim, em sendo uma estrutura cuja composição é marcadamente interinstitucional, convém estabelecer mecanismos de articulação bastante explícitos, para garantir os compromissos das entidades participantes, com característica de equipe interdisciplinar.

\section{Dimensäo Operacional}

O aspecto mais importante a este nivel é que a vigilância sempre deve estar ligada à ação. Tão relevante quanto a sua capacidade preditiva é a sua utilidade em contribuir para uma resposta conseqüente aos problemas identificados. Assim, em termos de vigilância nutricional, será tanto mais efetiva quanto maior a capacidade do sistema de saúde, frente a esses problemas, de responder de modo resolutivo.

Operacionalmente, cumpre evitar que o Sisvan estabeleça paralelismos ou duplique funções de outros sistemas, em especial o de informaçāo em saúde. Por sua vez, a nível de campo, é recomendável respeitar a capacidade operativa de cada uma das entidades executoras. Então, seria preferível iniciar a implantação do sistema pelas unidades dotadas de melhores recursos, assegurando o êxito do instrumento e servindo de modelo, a exemplo das unidades sentinelas, em alguns paises.

É indispensável, também, que disponha de recursos para desempenhar com eficiência as ações previstas, especificamente porque se trata de um processo contínuo de informações.

\section{Dimensão Social}

A credibilidade do Sisvan depende do seu compromisso social, isto é, de produzir dados que fundamentem modificações de políticas e de programas, de modo que correspondam à realidade epidemiológica, e de exercer influência significativa na aplicação de novas medidas, na alteração de metas, na alocação de recursos etc. Para tanto, devem ser promovidos mecanismos de divulgação oportuna e sistemática das informaçōes, principalmente junto aos usuários, dentre os quais se inscrevem os integrantes de niveis decisórios. Por isso, convém envidar esforços no sentido de intensificar a velocidade de análise dos resultados que são retroalimentados. Essa prática tem ·um duplo benefício, conforme a experiência de alguns especialistas: melhora a confiabilidade dos dados que se coletam e analisam e, igualmente, a utilidade do Sisvan, ao possibilitar uma relação mais estreita entre os resultados e as açōes.

\section{PERSPECTIVAS}

É promissor o fato de que os aspectos nutricionais têm sido valorizados, ultimamente, como referencial obrigatório das políticas sociais e econômicas. Dentro dessa perspectiva, três documentos devem ser destacados:

- a lei $\mathrm{n}^{\mathrm{Q}}$ 8080, de 19.09.90, instituindo o Sistema Único de Saúde - Sus, que, no Artigo $6^{2}$, Inciso IV, destaca a vigilância nutricional como um dos seus campos de atuação;

- o Plano Qüinqüenal de Saúde para o período 1990/1995, do Ministério da Saúde;

- o Projeto de Reconstrução Nacional, lançado pela Presidência da República, em março de 1991.

É nesse contexto que o Inan deve procurar o seu espaço de atuação, com credenciais que lhe conferem a lei de sua criação e a experiência adquirida em sua trajetória, onde três momentos demarcaram sua identidade e relevante papel:

- o primciro, vivenciado na formulação e implementaçāo do II Pronan, marco aquisitivo de experiências de busca da convergência interinstitucional, com vistas a novas atitudes e novos compromissos das instituições envolvidas;

- o segundo, com a realização da Pesquisa Nacional de Saúde e Nutrição, que, certamente, se inscreve como um dos mais significativos estudos sociais executados no país neste decênio;

- o terceiro, a proposta do Sisvan, consubstan- 
ciada nas Portarias Ministeriais ns 1156/MS e $1273 / \mathrm{MS}$, de 1990 , com ajuste paulatino às medidas e posicionamentos adotados para a concretização do Sistema Único de Saúde, conforme discriminações no Plano de Ação do Ministério da Saúde e no Projeto de Reconstrução Nacional. No primeiro, estão definidas as situações sistêmicas e as situações especificas que serão desenvolvidas; no segundo, o compromisso de implantar um modelo de atendimento capaz de alterar positivamente os niveis de saúde da população, prevendo investimentos, no curso de cinco anos, estimados em 120 bilhões de dólares, que promoverão uma mudança profunda no perfil de saúde do pais.

Diante de quadro tão promissor, considero mais importante fortalecer a politica setorial do Sisvan do que dispender esforços ingentes na coordenação de outros setores influentes na política de alimentação e nutrição, que seguem cumprindo a sua função. Cabem, entretanto, o alerta, a cooperação, o intercâmbio e a reivindicação.

No âmbito do setor saúde, o Inan deve dispor de informação precisa, completa, oportuna, regular e contínua,a fim de estar em condições de recomendar, sobre bases objetivas e científicas, as medidas de ação no campo nutricional, inclusive para subsidiar a Direção Nacional do Sistema Único de Saúde em duas de suas competências, conforme prescrevem o Inciso I do Art. 16 da lei $n^{0} 8080$ (Lei Orgânica da Saúde) - formular, avaliar e apoiar políticas de alimentação e nutrição, e o Inciso II do Art. 35 - definir o perfil epidemiológico da população a ser coberta, para o estabelecimento dos valores a serem transferidos pelo Ministério da Saúde aos estados e municípios.

Convém insistir que o Sisvan somente é útil se proporcionar a informação requerida no momento e lugar em que se necessita. $O$ imediatismo da utilização implica em que a atividade de vigilância deve ser nitidamente de natureza local, com o apoio dos níveis regional e central, aos quais compete uma elaboração mais detalhada dos dados, criticamente desenvolvida.

Este ponto de vista encontra respaldo nas propostas de descentralização, cuja tônica é a municipalização. Se os problemas se detectam a nível local, é a esse nível que interessam decisões rápidas, eficazes, de modo a evitar o agravamento da situação. Por sua vez, é nesse espaço que se trabalha com a comunidade de forma direta, cuja participação é imprescindível (Arruda, 1987; Opas, 1990), fazendo com que se torne concreta a contribuição do Sisvan.

Alude acertadamente Becker (1991) que, $d$ medida que se utilizam os dados em níveis mais próximos do local onde os eventos ocorreram, e onde se geraram os dados, cresce a necessidade de que os mesmos sejam mais oportunamente disponiveis, de que as análises sejam objetivas e rápidas, a fim de que as decisões possam ser prontamente tomadas e as ações necessárias, implementadas.

A Pesquisa Nacional de Saúde e Nutrição PNSN - já definiu o perfil nutricional do brasileiro (MS/Inan, 1990) e ensejou abordagens de significantes aspectos, a exemplo do mapeamento de áreas carentes (Monteiro, 1991) e a avaliação dos segmentos populacionais beneficiados pela suplementação alimentar (Peliano, 1990). Em virtude de ser bastante amplo o elenco de variáveis exploradas pela PNSN, cujo tratamento necessita ser adequado e objetivamente desenvolvido, a alguns núcleos especializados podem ser atribuídos esses desdobramentos analíticos. Agora, resta ampliar e consolidar a obtenção de informações dos grupos que estão sofrendo o problema, com o nível de agregação dos dados de acordo com diferentes parâmetros epidemiológicos, coerente com o conceito de cobertura adotado pelo setor saúde, que significa conhecer a população e ter informações sempre atualizadas sobre a mesma. Relativamente à nutrição, este é o importante e intransferível papel que compete ao Sisvan.

Deste modo, o Sisvan deixaria de ser números frios, carentes de significação e passaria a catalisar uma cadeia contínua de atividades que repercutem umas sobre as outras: informação gera ação, que produz resultados, e estes geram novos dados e informações. $E$ não seríamos passiveis da crítica que fez Lord Boyd-Orr (Prêmio Nobel e primeiro Diretor da Fao), há 30 anos: as pessoas nos pedem alimentos e nós lhes damos estatisticas. 


\section{RESUMO}

ARRUDA, B. K. G. de. Sistema de Vigilância Alimentar e Nutricional. Frustraçōes, Desafios e Perspectivas. Cad. Saúde Públ., Rio de Janeiro, 8 (1): 96-101, jan/abr, 1992.

$O$ autor refere o valor da vigilância alimentar e nutricional, as frustrações decorrentes da sua implementação, os desafios que se apresentam ao desenvolviemnto do Sisvan, analisando-os em várias dimensões política, técnica, organizacional, operacional e social - e as perspectivas surgidas com a valorização, ultimamente, dos aspectos nutricionais como referencial obrigatório das políticas sociais e econômicas. Um ponto enfatizado é ser a vigilância uma atividade de natureza eminentemente local, que encontra respaldo nas propostas de descentralização, que se concretizam na municipalização dos serviços de saúde.

Palavras-Chave: Vigilância Alimentar e Nutricional; Avaliação Nutricional

\section{REFERÊNCIAS BIBLIOGRÁFICAS}

ARRUDA, B. K. G., 1987. A comunidade e os problemas nutricionais: é importante saber onde estão e quantos são os desnutridos? Revista do Instituto Materno Infantil de Pernambuco, 1. 1987. Nutrição para todos - o que pode fazer o setor saúde? Revista do Instituto Materno Infantil de Pernambuco, 1.

BECKER, R. A., 1991. Análise de Mortalidade delineamentos básicos. Brasilia: Ministério da Saúde/Organização Pan-americana da Saúde.

CADERMARTORI, L., 1990. Acesso d informação: limites culturais do desenvolvimento. (Acompanhamento de Políticas Públicas, $n^{2} 26$ ). Brasilia: IPEA

MONTEIRO, C. A., 1991. O Mapa da Pobreza no Brasil. São Paulo: Nupens/Universidade de São Paulo.

MS/INAN, 1990. Relatório preliminar da PNSN. Brasilia: Instituto Nacional de Alimentação e Nutrição.

ORGANIZACION PANAMERICANA DE LA SALUD, 1990. Desarrollo y fortalecimiento de los sistemas locales de salud en la transformacion de los sistemas nacionales de salud: la participacion social. Washington, D.C.: OPS.
PELIANO, A. M., 1990. Quem se beneficia dos programas de suplementação alimentar (Texto para discussão nº 205). Brasilia: IPEA. 